\title{
Research Article \\ Optimising the (Microwave) Hydrothermal Pretreatment of Brewers Spent Grains for Bioethanol Production
}

\author{
Stuart Wilkinson, ${ }^{1}$ Katherine A. Smart, ${ }^{2}$ and David J. Cook ${ }^{1}$ \\ ${ }^{1}$ Brewing Science Section, Division of Food Sciences, The University of Nottingham, Sutton Bonington Campus, \\ Loughborough, Leicestershire LE12 5RD, UK \\ ${ }^{2}$ SABMiller PLC, SABMiller House, Church Street West, Woking, Surrey GU21 6HS, UK \\ Correspondence should be addressed to David J. Cook; david.cook@nottingham.ac.uk
}

Received 13 July 2015; Accepted 20 October 2015

Academic Editor: Stamatios Kalligeros

Copyright (C) 2015 Stuart Wilkinson et al. This is an open access article distributed under the Creative Commons Attribution License, which permits unrestricted use, distribution, and reproduction in any medium, provided the original work is properly cited.

For the production of bioethanol from lignocellulosic biomass, it is important to optimise the thermochemical pretreatment which is required to facilitate subsequent liberation of monomeric sugars. Here, we report optimisation of pretreatment conditions for brewers spent grains (BSG) with the main objectives of (1) working at commercially relevant high solids content, (2) minimising energy and chemical inputs, and (3) maximising downstream sugar yields. Studies indicated there to be a play-off between pretreatment solids content, the usage of an acid catalyst, and pretreatment temperature. For example, yields of $80-90 \%$ theoretical glucose could be obtained following pretreatment at $35 \% \mathrm{w} / \mathrm{v}$ solids and $200^{\circ} \mathrm{C}$, or at $140-160^{\circ} \mathrm{C}$ with addition of $1 \% \mathrm{HCl}$. However, at very high solids loadings $(40-50 \% \mathrm{w} / \mathrm{v})$ temperatures of $180-200^{\circ} \mathrm{C}$ were necessary to attain comparable sugar yields, even with an acid catalyst. The feasibility of producing bioethanol from feedstocks generated using these protocols was demonstrated (but not optimised) at laboratory scale.

\section{Introduction}

Brewers spent grain (BSG) is a high tonnage coproduct of the brewing industry and is a lignocellulosic material which could potentially be used to produce bioethanol [1-4]. It contains a substantial proportion of sugars, present in bound form as complex carbohydrates. The main carbohydrate polymers present are cellulose and hemicellulose which typically comprise between $15-30 \%$ and $10-25 \%$, respectively, of barley malt-derived BSG $[2,5,6]$. This represents a significant potential source of fermentable carbohydrate, which could offer a higher value application for this waste stream than the current predominant use as cattle feed [1].

Liquid biofuel production from lignocellulosic materials normally requires a pretreatment step prior to enzymatic saccharification to improve the yields of fermentable sugars liberated. This is due to the recalcitrant nature of the lignocellulosic structures present in biomaterials and their resistance to enzymatic degradation $[7,8]$. Hydrothermal pretreatments operate at high temperatures (e.g., $120-200^{\circ} \mathrm{C}$ ) and pressures, and the deconstruction process is referred to as "autohydrolysis" when water present within the biomass matrix acts to hydrolyse hemicellulose and disrupt the lignocellulosic structure to enhance its subsequent enzymatic digestion. Such processes avoid usage of environmentally unfriendly, hazardous, or costly chemical reagents (e.g., ammonia or ionic liquids) but have been found to require high temperatures $\left(\mathrm{ca} .200^{\circ} \mathrm{C}\right)$ to achieve satisfactory deconstruction when using lignocellulosic materials such as wheat straw and corn stover $[8,9]$. Addition of a catalytic reagent, such as dilute concentrations of a strong acid (e.g., $\mathrm{HCl}, \mathrm{HNO}_{3}$, or $\mathrm{H}_{2} \mathrm{SO}_{4}$ ), has been shown to improve the efficiency of hydrothermal pretreatment processes and permits the use of somewhat lower process temperatures. The additional acid reagent cost can thus be outweighed by energy savings, whilst still achieving the process objectives [10-13]. The primary mechanism of both the autohydrolytical and acid catalysed hydrothermal pretreatment of lignocellulosic biomass involves removal of hemicellulose, which exposes the remaining cellulose fraction thus making it more amenable to 


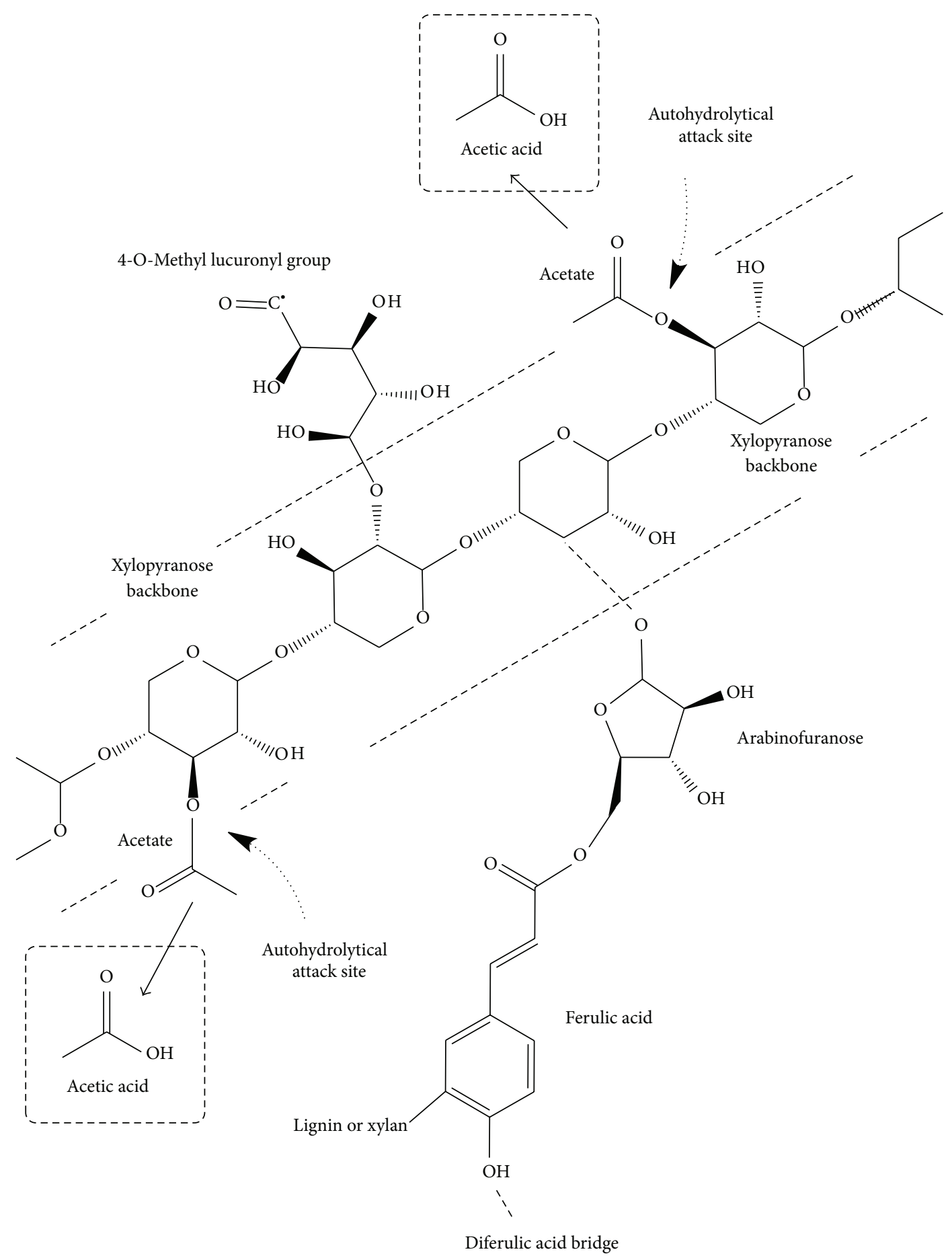

FIGURE 1: Proposed scheme for the autohydrolytical cleavage of acetate groups to liberate free acetic acid for further hydrolytic breakdown of hemicellulose.

enzymatic digestion $[10,14,15]$. The mechanism of autohydrolytical pretreatment involves cleavage of acetylated xylose units from hemicellulose, yielding free acetic acid residues (Figure 1). The acetic acid thus released then acts to further hydrolyse the remaining hemicellulose present. Use of an additional acid catalyst in theory reenforces this acid catalysed hydrolysis.
Lignocellulosic biomass pretreatment processes must be optimised, in order to determine conditions which most efficiently enhance the subsequent saccharification of that specific substrate. This aspect is highly significant to the viability of bioethanol production processes, as has been highlighted by life cycle assessment (LCA) studies based on other lignocellulosic materials; the pretreatment step is 
usually identified as the most energy-intensive aspect of the overall process [7, 16-18]. The research described in this paper addresses the need for viable processes to operate at high solids content (up to $50 \% \mathrm{w} / \mathrm{v}$ ); otherwise, the cost of heating process water becomes prohibitive, even though yield and material handling considerations might suggest working at lower solids loadings. The prevalence of hydrothermal and steam explosion pretreatments in existing pilot plant and lignocellulosic bioethanol demonstration facilities indicates their favourability (both practically and economically) when deconstructing lignocellulosic biomass on a commercial scale [19-23]. We thus opted to evaluate their application to BSG, due to their relative simplicity, and hence cost-effectiveness. Microwave irradiation (dielectric heating) offers an alternative method for the rapid and controlled generation of heat within materials $[24,25]$, to stimulate hydrothermal reaction conditions. It has also been speculated that rapid internal heating of water distributed throughout a lignocellulosic material could help to disrupt that structure effectively. Microwave based pretreatment has been shown to work effectively with many lignocellulosic feedstocks such as rape straw, liberating ca. $54 \%$ of theoretical glucose [26], sugarcane bagasse, liberating a reducing sugar yield of $0.83 \mathrm{~g} / \mathrm{g}$ dry biomass [27], wheat straw [28, 29], and even BSG, liberating $62 \%$ of all arabinoxylans and feruloylated arabinoxylooligosaccharides [30].

The present research aimed to evaluate the feasibility of a bioethanol production process based on BSG, with focus on optimising the pretreatment step. For the reasons outlined above, we elected to evaluate autohydrolytical and acid catalysed hydrothermal pretreatment of BSG at commercially relevant solids loadings ( $>25 \% \mathrm{w} / \mathrm{v})$ and using a microwave reactor. It should be noted that the microwave reactor used in these studies was a piece of laboratory apparatus, designed for rapid and accurately controlled heating. Following enzymatic saccharification, we conducted trial fermentations using Saccharomyces cerevisiae to assess the fermentability of the feedstocks produced from BSG and the resultant ethanol yields.

\section{Materials and Methods}

2.1. Reagents. All reagents were of AnalaR grade and obtained from Sigma-Aldrich (UK) and Fisher Scientific (UK). All water used was deionised reverse osmosis and of $\geq 18$ megaohm purity (Purite Select Ondeo IS water system, Purite, UK).

2.2. BSG. Brewers spent grains (BSG) were obtained from the SABMiller $10 \mathrm{hl}$ Research Brewery (Sutton Bonington, UK) from a high gravity brewing process using $100 \%$ malted barley. The BSG was then dried overnight at $105^{\circ} \mathrm{C}$ and ground to a particle size of less than $212 \mu \mathrm{m}$ to ensure adequate homogeneity prior to sampling. Typical composition of brewers spent grains is given in Table 1 .

2.3. Pretreatment of BSG. Both autohydrolytical and dilute acid catalysed microwave based pretreatments of BSG were conducted using a laboratory scale Monowave 300
TABLE 1: Typical compositional analysis of brewers spent grains [13].

\begin{tabular}{lc}
\hline BSG component & $\%(\mathrm{w} / \mathrm{w})$ \\
\hline Starch & $4.8 \pm 0.46$ \\
Protein & $26.6 \pm 0.38$ \\
Ash & $2.7 \pm 0.070$ \\
Lipid & $5.2 \pm 2.1$ \\
Lignin & $9.9 \pm 1.4$ \\
Cellulose (glucose) & $19.2 \pm 1.4$ \\
Hemicellulose & $18.4 \pm 3.7$ \\
$\quad$ of which xylose & $11.3 \pm 1.2$ \\
Moisture content & $7.4 \pm 0.80$ \\
Other & 5.8 \\
\hline
\end{tabular}

Data are the mean \pm SD of 3 replicate measurements.

microwave synthesis reactor (Anton Paar Gmbh, Graz, Austria) using both infrared and ruby based fibre optic thermometers for accurate temperature control. Autohydrolytical pretreatment was investigated using a $120-200^{\circ} \mathrm{C}$ temperature range, a reaction time range of $1-15 \mathrm{~min}$, and over a $2.5-35 \%(\mathrm{w} / \mathrm{v})$ range of solids loadings. Acid catalysed pretreatment was conducted using $1 \% \mathrm{HCl}(\mathrm{v} / \mathrm{v})$ using a temperature range of $120-200^{\circ} \mathrm{C}$, a reaction time range of 1$15 \mathrm{~min}$ and a $30-50 \%(\mathrm{w} / \mathrm{v})$ range of solids loadings.

The experimental design software DesignExpert (StatEase Inc., Minneapolis, MN, USA) was employed to create experimental designs that would reduce the total number of experimental runs whilst still accurately statistically modelling the data to determine any variance.

BSG (0.7-5.0 g) was accurately weighed into the specified glass G30 $(30 \mathrm{~mL})$ microwave reaction vessels (Anton Paar Gmbh, Graz, Austria) with $8.0-25 \mathrm{~mL}$ water to achieve the correct solids loading. The experimental runs were then heated to the correct temperature and for the desired time period and then cooled initially through the microwaves' own air based cooling system to $70^{\circ} \mathrm{C}$ and then finally through submersion into cold water to stop any further reactions. Any remaining hydrolysate (liquid fraction) after pretreatment was then sampled and analysed for sugar concentration and metabolic inhibitor concentrations via HPLC. Pretreated slurries generated when using very high solids loadings did not produce any hydrolysate for analysis as the biomass absorbed all the free liquid. After each of the pretreatments, the remaining material was transferred into a $50 \mathrm{~mL}$ centrifuge tube and the $\mathrm{pH}$ was adjusted to $5.0 \pm 0.1$ via $40 \% \mathrm{NaOH}(\mathrm{w} / \mathrm{v})$. The remaining solid residue was then exhaustively washed with water, conducted by resuspension and centrifugation at $5000 \mathrm{rpm}$ for $10 \mathrm{~min}$, discarding the supernatant each time. The remaining residues were then dried overnight at $60^{\circ} \mathrm{C}$.

2.4. Enzymatic Saccharification of Pretreated BSG. Cellulolytic enzymes were used for the saccharification of all the pretreated BSG derived solid residues described in Section 2.3 in order to determine the efficacy of the different pretreatments. All enzyme hydrolysis reactions of the pretreated residues were conducted using 24-hour incubation 
periods at $50^{\circ} \mathrm{C}$ with agitation at $150 \mathrm{rpm}$ (MaxQ 4358 shaking incubator, Thermo Scientific, UK) using $50 \mathrm{mM}$ sodium citrate buffer $(\mathrm{pH} 5.0 \pm 0.1)$ to dilute to the required solids loading. Enzymatic saccharification was initially conducted using a low solids loading protocol $(2.5 \% \mathrm{w} / \mathrm{v})$ with lyophilised Celluclast cellulase from Trichoderma reesei (ATTC 26921, Sigma-Aldrich, UK) using a substantial excess of enzyme to determine the maximum theoretical sugar concentration obtainable from each different pretreatment protocol (i.e., purely to determine the efficacy of the pretreatment and not representing a commercially applicable process in terms of enzyme dosing and loading rates). $1 \mathrm{~g} / \mathrm{L}$ solution of the Celluclast cellulase was produced using $50 \mathrm{mM}$ sodium citrate buffer $(\mathrm{pH} 5.0 \pm 0.1)$ and hydrolysis was conducted using $200 \mathrm{mg}$ residue with $40 \mathrm{~mL}$ of the cellulase solution. After the 24-hour incubation, samples were centrifuged at $5000 \mathrm{rpm}$ for $10 \mathrm{~min}$ and the supernatant was sampled for quantification of sugars via HPLC. For the larger scale experiments designed to produce a sufficient quantity of feedstock to allow trial fermentations to be conducted, a high solids loading, low enzyme dose enzymatic saccharification protocol was conducted using Novozymes Cellic CTec2 (kindly supplied by Novozymes A/S, Demark) as this was considered to be more commercially applicable and more cost-effective (due to the high cost of Celluclast cellulase; ca. $£ 90 / 10 \mathrm{KU}$ enzyme) and thus reflects closer a large scale commercial bioethanol production process. Cellic CTec2 enzymatic hydrolysis reactions were conducted using an enzyme dosage of $20 \mu \mathrm{L}$ CTec 2 per $200 \mathrm{mg}$ residue (20 FPU/g biomass) dispersed in the required volume of $50 \mathrm{mM}$ sodium citrate buffer $(\mathrm{pH} 5.0 \pm 0.1)$ to achieve a $15 \%(w / v)$ solids loading. The Cellic CTec2 had a total cellulase activity of $204 \mathrm{FPU} / \mathrm{mL}$ in undiluted format which was determined according to the method described in [31]. After enzymatic saccharification the Cellic CTec2, digested samples were treated as for the Celluclast protocol above. The concentrations of glucose initially present in the Cellic CTec2 enzyme preparation were also quantified by HPLC and subtracted from the final saccharification sugar yields to allow accurate calculation of achieved theoretical sugar yields.

2.5. Trial Fermentations of Two Optimised Feedstocks. Trial fermentations were conducted using two feedstocks (selected due to their high sugar yields) from both an optimised autohydrolytical pretreatment $\left(200^{\circ} \mathrm{C}\right.$ for $\left.10 \mathrm{~min}\right)$ and an optimised acid catalysed $(1 \% \mathrm{HCl})$ hydrothermal pretreatment $\left(160^{\circ} \mathrm{C} 5 \mathrm{~min}\right)$ of BSG with the pretreatments both conducted at $30 \% \mathrm{w} / \mathrm{v}$ solids loading. The subsequent enzyme saccharification step was conducted using the Novozymes Cellic CTec2 protocol described in Section 2.4. These trial fermentations were not optimised and were included as proof of principle that ethanol could be produced from feedstocks generated using the pretreatment processes developed herein.

The fermentations were conducted (using $100 \mathrm{~mL}$ of each specific feedstock) in glass serum bottles $(125 \mathrm{~mL}$; Wheaton, USA) fitted with air-tight rubber septa, in order to maintain as anaerobic an environment as possible. Custom made nonreturn valves were used to allow the escape of fermentation gases (primarily $\mathrm{CO}_{2}$ ) whilst minimising air input. Vessels were inoculated by transfer of an aliquot of a propagated cell suspension of S. cerevisiae NCYC479 in order to achieve a pitching rate of approximately $10^{6}$ cells $/ \mathrm{mL}$. S. cerevisiae NCYC479 is a sake brewing yeast strain and was used due to its high ethanol tolerance phenotype. The yeast culture was initially grown in $10 \mathrm{~g} / \mathrm{L}$ yeast extract, $20 \mathrm{~g} / \mathrm{L}$ peptone, and $20 \mathrm{~g} / \mathrm{L}$ glucose (YPD) in an orbital shaker at $150 \mathrm{rpm}$ at $15^{\circ} \mathrm{C}$ under aerobic conditions for 5 days.

Fermentations were conducted at $15^{\circ} \mathrm{C}$ (MIR-253 incubator, Sanyo Electric Co., Japan) with magnetic stirring at $120 \mathrm{rpm}$. The fermentation temperature (whilst possibly not the most efficient temperature for rapid bioethanol production) was selected because it is similar to the sake fermentation temperature from which the strain originated. Full optimisation of the fermentation stage was considered beyond the scope of this paper. Fermentation progression was tracked by the weight loss of vessels as a result of the liberation of $\mathrm{CO}_{2}$ associated with the conversion of sugars to ethanol. Whilst this is perhaps not the most sensitive method of tracking fermentation progression, it should highlight any major fermentation issue such as a long lag phase or stuck fermentation due to a nutrient deficiency of some sort in the feedstock. Due to the very small volume and sealed nature of the fermentation vessels, it was not feasible to take and analyse time-point samples across fermentation. The fermentation vessels were accurately weighed at frequent intervals until a constant weight was achieved which was considered to indicate the end of the fermentation. Upon completion of the fermentation, samples were taken for HPLC analysis of ethanol. All fermentations were conducted in triplicate.

\subsection{Quantification of Total Glucose and Xylose Concentrations} in the Pretreated BSG. Total glucose and xylose concentrations in the pretreated solid residues were used for the determination of \% theoretical sugar yields after enzymatic saccharification and also used for calculation of cellulose and hemicellulose content of the pretreated residues after stoichiometric correction for dehydration. Complete acid hydrolysis of both the starting BSG and the solid residues generated after pretreatment were conducted using a an updated version of the assay outlined by Dubois et al. [32] to determine total glucose and xylose concentrations. $30 \mathrm{mg}$ of biomass was weighed into a Pyrex reaction vessel; $1 \mathrm{~mL}$ of $12 \mathrm{M} \mathrm{H}_{2} \mathrm{SO}_{4}$ was added and then incubated at $37^{\circ} \mathrm{C}$ for 1 hour. $11 \mathrm{~mL}$ of water was added to the sample to dilute the acid to $1 \mathrm{M}$ and this was incubated at $100^{\circ} \mathrm{C}$ for a further 2 hours. The liberated monosaccharide concentrations were then quantified by HPLC. All analyses were conducted in triplicate.

\subsection{High Performance Liquid Chromatography (HPLC) Anal-} $y$ sis. Monosaccharide concentrations were quantified via HPLC using an ICS3000 system (Dionex, USA) using a pa20 column (150 mm × $3.0 \mathrm{~mm}$; Dionex, USA) and pulsed amperometric electrochemical detection (PAD; Dionex, USA). The chromatographic conditions were as follows: isocratic elution with $10 \mathrm{mM} \mathrm{NaOH}$ at $0.5 \mathrm{~mL} / \mathrm{min}$ flow rate with a column 
regeneration step using $200 \mathrm{mM} \mathrm{NaOH}$ at $0.5 \mathrm{~mL} / \mathrm{min}$. Data were acquired using Chromeleon Chromatography software (Version 6.80, Dionex softron, Germering, Germany). Quantification was performed by comparison of peak areas of authentic standards. Metabolic process inhibitors were quantified by HPLC using UV detection at $280 \mathrm{~nm}$ (2695 HPLC system and 996 Photodiode Array Detector, Waters, USA) with UV spectra for secondary confirmation. The chromatographic conditions were as follows: Techsphere ODS C18 column $(5 \mu \mathrm{m}, 4.6 \mathrm{~mm} \times 250 \mathrm{~mm}$; HPLC Technologies, $\mathrm{UK})$ at ambient temperature. The mobile phase was a binary mixture of $1 \%$ acetic acid (solvent $\mathrm{A}$ ) and methanol (solvent B) with an overall flow rate of $1.0 \mathrm{~mL} /$ minute. The system was operated in gradient mode, ramping from $20 \%$ to $50 \%$ methanol over 30 minutes with a $100 \%$ methanol column cleaning phase and a 9-minute reequilibration period. The sample injection volume was $10 \mu \mathrm{L}$. Data were recorded using Millennium Chromatography software (Waters, USA). Quantification was performed by comparison of peak areas of a range of authentic standards.

Final ethanol concentrations generated during the fermentation trials were also quantified by HPLC. The system consisted of an AS-2055 Intelligent Autosampler and a PU1580 Intelligent HPLC Pump (Jasco, Japan) utilising a Rezex ROA Organic Acid H+ organic acid column $(5 \mu \mathrm{m}, 7.8 \mathrm{~mm} \times$ $300 \mathrm{~mm}$; Phenomenex, UK) operated at ambient temperature. The method utilised isocratic elution using a mobile phase of $0.005 \mathrm{~N} \mathrm{H}_{2} \mathrm{SO}_{4}(0.5 \mathrm{~mL} / \mathrm{min})$ and a Refractive Index cell (RI-2031 Intelligent Refractive Index detector, Jasco, Japan) for detection. The injection volume was $10 \mu \mathrm{L}$. Data were acquired using the Azur software package v. 4.6.0.0 (Datalys, France). Quantification was performed by comparison of peak areas of authentic ethanol standards.

All experiments (pretreatments, enzymatic hydrolysis reactions, and fermentations) were conducted in triplicate (biological replication).

\section{Results and Discussion}

The gross composition of the BSG sample used in this study was as previously reported [13] and is included in Table 1. Analysis indicated that approximately $41 \%$ of the material mass was due to carbohydrate polymers (principally cellulose and hemicellulose). This represents a substantial fraction of BSG with the potential to be deconstructed into fermentable sugars for the production of bioethanol.

Sections 3.1 and 3.2 report results from a series of optimisation experiments aimed at maximising the sugar concentrations liberated from BSG (postenzymatic saccharification) using a range of either autohydrolytical or acid catalysed hydrothermal pretreatments. An excess of Celluclast cellulase was used in each case for saccharification, in order to establish the efficacy of each specific pretreatment, and did not reflect a commercially viable enzyme dosage. However, Section 3.3 describes the fermentation of feedstocks produced under more commercially relevant saccharification conditions, using a low dose of Novozymes Cellic CTec2 at high solids loading.

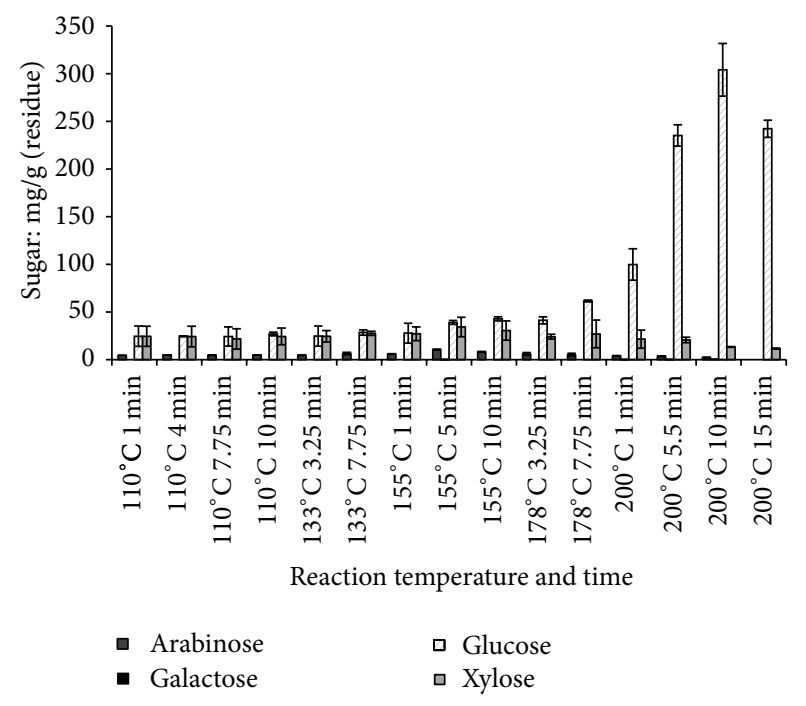

FIGURE 2: The impact of pretreatment reaction temperature (110$200^{\circ} \mathrm{C}$ ) and reaction time $(1-10 \mathrm{~min})$ on sugar yields following enzymatic saccharification of the BSG pretreatment solid residue. Treatment conditions varied according to D-optimal algorithm (see Table 2 for experimental design). Preliminary screening of autohydrolytical pretreatment of BSG at $2.5 \%(\mathrm{w} / \mathrm{v})$ solids loading. $24 \mathrm{~h}$ enzyme incubation $\left(50^{\circ} \mathrm{C}\right)$ using $200 \mathrm{mg}$ residue to $40 \mathrm{~mL}$ of a $1 \mathrm{~g} / \mathrm{L}$ Celluclast solution buffered to $\mathrm{pH} 5.0 \pm 0.1$. Data are the mean \pm $\mathrm{SD}$ of three replicate measurements.

\subsection{Autohydrolytical Pretreatment of BSG}

3.1.1. Hydrothermal Pretreatment (Autohydrolysis) at Low Solids Loading. Preliminary work investigated the impact of temperature $\left(110-200^{\circ} \mathrm{C}\right)$ and time $(1-10 \mathrm{~min})$ on the efficacy of pretreatments at low solids loading $(2.5 \% \mathrm{w} / \mathrm{v})$. As BSG has already been through an industrial process (the malting and mashing steps of the brewing process), the experiment was designed to evaluate whether lower temperatures could be used to pretreat BSG, as compared to those known to be required for other lignocellulosic biomass (e.g., wheat straw). DesignExpert software was used to create a Doptimal design space that would rapidly screen a wide range of pretreatment temperatures and reaction times (whilst minimising the total number of experiments needed) in order to find a suitable set of conditions for further optimisation. A total of 20 pretreatments were conducted, enabling the measured outputs to be modelled across the design space (Table 2).

Quantification of the sugars liberated following enzymatic saccharification (using an excess of Celluclast cellulase) indicated that temperatures approaching $200^{\circ} \mathrm{C}$ and reaction times of at least $5 \mathrm{~min}$ were required in order to achieve glucose yields of $300 \mathrm{mg} / \mathrm{g}$ pretreated BSG (Figure 2), whereas at lower process temperatures $\left(110-150^{\circ} \mathrm{C}\right)$ glucose yields of only $50 \mathrm{mg} / \mathrm{g}$ were achieved. Thus, autohydrolysis of BSG under the hydrothermal conditions used here required temperatures of ca. $200^{\circ} \mathrm{C}$ to attain high sugar yields following enzymatic saccharification of the pretreated BSG solid residue. 
TABLE 2: Experimental design used for preliminary screening of the simultaneous impacts of reaction temperature $\left(110^{\circ} \mathrm{C}-200^{\circ} \mathrm{C}\right)$ and reaction time (1-10 $\mathrm{min}$ ) during microwave based autohydrolytical pretreatment of BSG according to a D-optimal design space*. Autohydrolytical pretreatment utilized a Monowave 300 microwave synthesis reactor with G30 vessels (Anton Parr), 2.5\% w/v solids loading.

\begin{tabular}{lcc}
\hline Run & $\begin{array}{c}\text { Factor } 1 \\
\text { A: temp. } \\
\left({ }^{\circ} \mathrm{C}\right)\end{array}$ & $\begin{array}{c}\text { Factor } 2 \\
\text { B: time } \\
(\mathrm{min})\end{array}$ \\
\hline 1 & 110 & 1 \\
2 & 110 & 7 \\
3 & 155 & 5.5 \\
4 & 110 & 10 \\
5 & 200 & 5.5 \\
6 & 200 & 5.5 \\
7 & 200 & 1 \\
8 & 200 & 1 \\
9 & 110 & 1 \\
10 & 155 & 1 \\
11 & 200 & 10 \\
12 & 155 & 5.5 \\
13 & 133 & 3.25 \\
14 & 155 & 10 \\
15 & 133 & 7.75 \\
16 & 200 & 1 \\
17 & 200 & 10 \\
18 & 178 & 7.75 \\
19 & 110 & 4 \\
20 & 178 & 3.25 \\
\hline 10 & & \\
\hline
\end{tabular}

${ }^{*}$ D-optimal experimental design created using DesignExpert (Stat-Ease, USA) using a series of reaction combinations (temperatures and times) from which the $\mathrm{D}$-optimal algorithm chose the treatment combinations to include in the design. This reduced the total number of experiments needed to be conducted from that of a full factorial experimental design.

3.1.2. Hydrothermal Pretreatment (Autohydrolysis) at High Solids Loading. A total of 19 pretreatments at $200^{\circ} \mathrm{C}$ were conducted using a D-optimal designed experiment (Table 3 ) with two factors varied: pretreatment solids loading (10-35\% $\mathrm{w} / \mathrm{v})$ and reaction time $(5-15 \mathrm{~min})$ and the response data were then modelled against these factors. The D-optimal experimental design was created using DesignExpert (StatEase, USA) using a series of reaction combinations (temperatures and times) from which the D-optimal algorithm chose which treatment combinations to include in the design. The use of a D-optimal experimental design reduced the total number of experiments needed to be conducted from that of a full factorial experimental design, whilst still providing statistically valid data.

(1) Analysis of the Liquid Fraction Generated Directly from the Pretreatment Step. Because the solid residue following hydrothermal pretreatment of lignocellulosic materials is enriched in cellulose and therefore contains the majority of available sugars, the liquor generated during pretreatment
TABLE 3: Experimental design used to simultaneously evaluate the impacts of variation of the \% solids loading and reaction time during microwave based autohydrolytical pretreatment of BSG at $200^{\circ} \mathrm{C}$ according to a D-optimal design space* . Autohydrolytical pretreatment utilized a Monowave 300 microwave synthesis reactor with G30 vessels (Anton Parr).

\begin{tabular}{lcc}
\hline Run & $\begin{array}{c}\text { Factor 1 } \\
\text { A: solids loading } \\
\text { \% (w/v) }\end{array}$ & $\begin{array}{c}\text { Factor } 2 \\
\text { B: time } \\
(\mathrm{min})\end{array}$ \\
\hline 1 & 35 & 5 \\
2 & 10 & 10 \\
3 & 22.5 & 10 \\
4 & 22.5 & 5 \\
5 & 35 & 15 \\
6 & 10 & 5 \\
7 & 10 & 15 \\
8 & 35 & 15 \\
9 & 35 & 5 \\
10 & 22.5 & 10 \\
11 & 22.5 & 15 \\
12 & 22.5 & 10 \\
13 & 35 & 10 \\
14 & 10 & 5 \\
15 & 16 & 7.5 \\
16 & 29 & 7.5 \\
17 & 16 & 12.5 \\
18 & 29 & 12.5 \\
19 & 10 & 15 \\
${ }^{*}$ D-optimal experimental design created using DesignExpert & (Stat-Ease, \\
USA) using a collection of reaction combinations (temperatures and times) \\
from which the D-optimal algorithm chose the treatment combinations to \\
include in the design. This reduced the total number of experiments needed \\
to be conducted from that of a full factorial experimental design.
\end{tabular}

is often overlooked as a potential source of fermentable sugars. Nevertheless, it represents a pool of additional sugars and may also be a source of high value chemicals (e.g., 5hydroxymethylfurfural or HMF); therefore, its compositional characterisation is desirable as a part of process optimisation.

Modelling of glucose released into the liquor during hydrothermal pretreatment at $200^{\circ} \mathrm{C}$ suggested that a maximum concentration of around $4.5 \mathrm{~g} / \mathrm{L}$ resulted from short holding times (ca. $5 \mathrm{~min}$ ) at high solids loadings $(35 \% \mathrm{w} / \mathrm{v}$; Figure 3(a)). At low solids loadings, an increase of pretreatment holding time over the range 5-15 min first increased and then decreased the glucose concentration in the pretreatment liquor. This is thought to represent a balance between the extent to which the more thermally labile amorphous regions of cellulose were broken down to release glucose and the subsequent degradation of glucose to HMF with prolonged holding at $200^{\circ} \mathrm{C}$. At high solids loadings, the predominant effect of increasing holding time was to reduce glucose concentrations released into the liquor, presumably once again due to degradation to generate HMF. The model of HMF concentration in the pretreatment liquors (Figure 3(c)) supports this hypothesis, since HMF concentrations were 


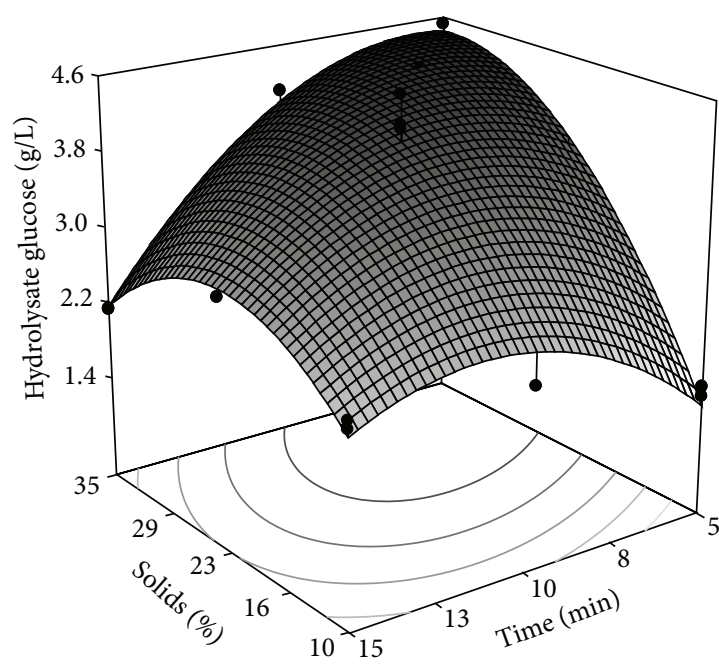

(a) Glucose

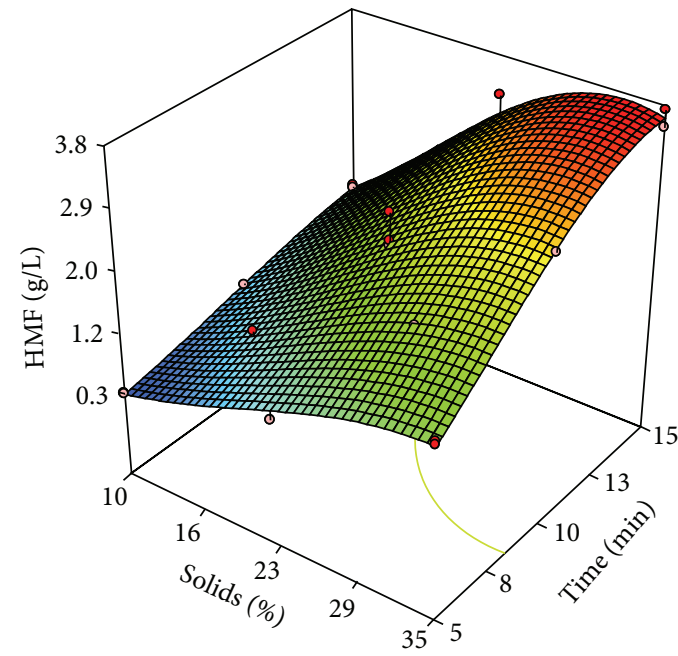

(c) 5-Hydroxymethylfurfural

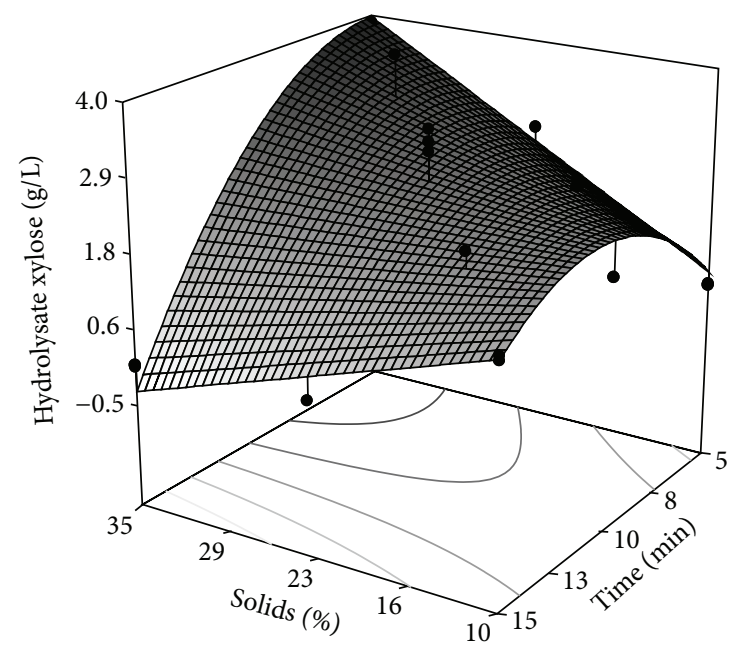

(b) Xylose

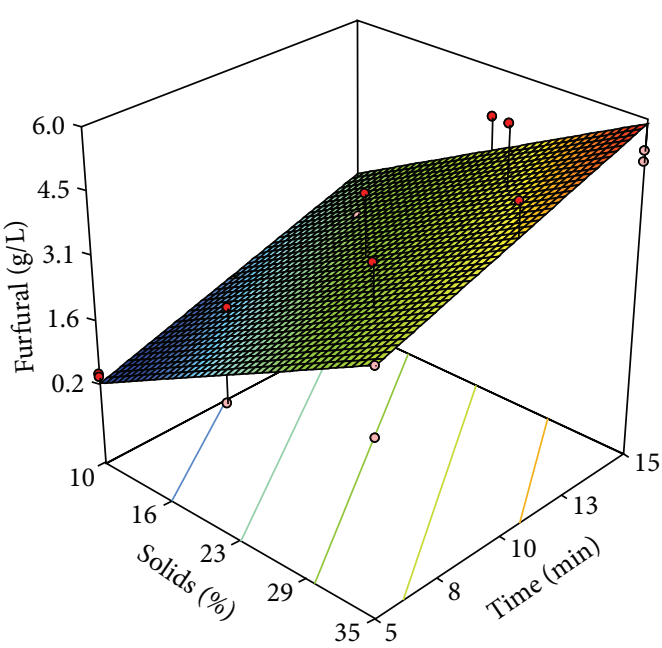

(d) Furfural

Figure 3: Design Expert 3D response surface models showing the effects of the factors (i) \% solids loading (w/v) and (ii) reaction time (min) during $200^{\circ} \mathrm{C}$ pretreatment of BSG (temperature as previously optimised) on the resultant sugar concentrations liberated directly into the pretreatment hydrolysate $(\mathrm{g} / \mathrm{L})$. (a) Glucose $\left(R^{2}: 0.84\right)$, (b) xylose $\left(R^{2}: 0.96\right)$, (c) 5-hydroxymethylfurfural $\left(R^{2}: 0.98\right)$, and (d) furfural $\left(R^{2}\right.$ : $0.81)$. Autohydrolytical pretreatment utilized a Monowave 300 microwave synthesis reactor with G30 vessels (Anton Parr).

maximal at the highest solids content $(35 \% \mathrm{w} / \mathrm{v})$ and longest treatment time.

Xylose in the pretreatment liquor originates from the hydrothermal breakdown of hemicellulose. The trends in xylose concentrations across the design space exhibited some similarity to the glucose results, with peak concentrations of $4.0 \mathrm{~g} / \mathrm{L}$ released at the highest solids content and shortest treatment time (Figure 3(b)). Once again, albeit with a slightly modified response surface, the analytical concentration of xylose is hypothesized to be a balance between its release through breakdown of hemicellulose polymers and its thermal degradation to products such as furfural (Figure 3(d)). In contrast to glucose, xylose hydrolysate concentrations exhibited a small linear decline with increasing solids loading at $15 \mathrm{~min}$ reaction time (from $1.8 \mathrm{~g} / \mathrm{L}$ to $0.55 \mathrm{~g} / \mathrm{L})$. Clearly, at $15 \mathrm{~min}$ treatment time, the onwards degradation of the released xylose outweighed the concentration effect of working at higher solids which was evident at a 5 min treatment time (Figure 3(b)). Furfural concentrations were maximal under these conditions (Figure 3(d)).

Evaluation of any pretreatment must also consider the degree of generation of downstream processing inhibitors, such as HMF and furfural which are generated from thermal degradation of hexose and pentose monosaccharides (resp.). These furan compounds can reduce the efficiency of the subsequent enzymatic hydrolysis and fermentation steps conducted downstream [33-36]. They are liberated into the hydrolysate (liquid fraction) generated during pretreatment, particularly when exposing materials to high temperatures for prolonged periods. Both HMF and furfural have well established inhibitory actions on many fermentative species such as Saccharomyces cerevisiae; hence, their production 
should be minimised wherever possible $[34,36]$. They primarily affect the redox balance of the cell, with furfural affecting the function of alcohol dehydrogenase (ADH) and $\mathrm{HMF}$ affecting nicotinamide adenine dinucleotide phosphate (NADPH) function.

Quantification of potential yeast-inhibitory compounds in the pretreatment liquor suggested that HMF and furfural were the only significant inhibitors detected, with furfural being present in greater concentrations than HMF (maximally $6.0 \mathrm{~g} / \mathrm{L}$ for furfural compared to $3.8 \mathrm{~g} / \mathrm{L}$ for $\mathrm{HMF}$ : Figures 3(c)-3(d), resp.). This was as expected, bearing in mind the known function of hydrothermal pretreatments in solubilising hemicellulose [37]. A general correlation was seen with increasing concentrations of both furfural and $\mathrm{HMF}$ as solids loading and reaction time increased. Whilst prolonged treatment time favoured furfural production across the design space, the solid loading during pretreatment had the greater impact on furfural concentration. HMF concentrations exhibited a different trend with a linear increase in response to increasing reaction time (at any given solids loading) but with a more significant effect (steeper linear ramp) at higher solids loadings compared to at lower solids loadings (Figure 3(c)). In contrast to the linear furfural concentration increase at all reaction times as solids loading increased, at longer reaction times (ca. $15 \mathrm{~min}$ ) HMF concentrations only increased until ca. 29\% solids loading, beyond which they began to plateau. However, with shorter reaction times (ca. $5 \mathrm{~min}$ ) an almost linear increase in $\mathrm{HMF}$ concentrations was observed with increasing solids loadings beyond ca. 25\% (w/v). The furfural concentrations of ca. $5 \mathrm{~g} / \mathrm{L}$ generated from autohydrolytical pretreatment of BSG at $200^{\circ} \mathrm{C}$ when using solids loadings greater than $29 \% \mathrm{w} / \mathrm{v}$ would be metabolically inhibitory for many fermentative species such as $S$. cerevisiae $[34,35]$ rendering some form of biomass washing or dilution necessary. However, fractionation of both furfural and HMF from a waste stream after such a biomass washing step could generate additional revenue due to the high value of both compounds in research and development as chemical intermediates for various industrially relevant compounds such as the solvent tetrahydrofuran (THF) and various plastics including polyesters [38, 39].

(2) Sugar Yields Achieved after the Enzymatic Hydrolysis Step. Following each pretreatment, the remaining solid residue was separated from the liquid fraction in order to remove potentially detrimental metabolic process inhibitors that would likely interfere with the subsequent enzymatic saccharification and fermentation steps. All pretreated biomass was then washed and dried. Compositional analysis of these solid residues was undertaken both to enable accurate calculation of theoretical sugar yields after enzymatic saccharification and to assess, to some extent, the physical impact of each pretreatment on the composition of BSG derived material. Hydrothermal pretreatments primarily target hemicellulose solubilisation and the subsequent liberation of its monomeric constituents into the liquid fraction. Consequently this results in enrichment of the more recalcitrant components, such as crystalline cellulose. Producing a material enriched in cellulose could be deemed favourable if the ultimate intention is to ferment glucose to bioethanol using C-6 hexose fermenting yeast strains.

The proportion of cellulose in solid residues of pretreatments across the design space (Table 1) is illustrated as a response surface in Figure 4(a). There was a linear trend of decreasing cellulose enrichment as solids loading was increased (Figure 4(a)) as a consequence of a smaller degree of hemicellulose solubilisation (Figure 4(b)). Reaction time appeared to be a less influential parameter in this model, with a small decrease in cellulose enrichment occurring as reaction time was increased at each solids loading.

The solid residues of pretreated BSG were then treated with an excess of Celluclast enzyme and the sugars released were determined by HPLC. Response surface models were fitted to this data to show the impacts of treatment time (5$15 \mathrm{~min}$ ) at solids loadings within $10-35 \% \mathrm{w} / \mathrm{v}$ on the concentrations of glucose (Figure 4(c)) and xylose (Figure 4(d)). At any given pretreatment reaction time increasing solids loading (during the pretreatment step) resulted in higher glucose yields (expressed as a percentage of theoretical maximum) following enzymatic saccharification. At 35\% w/v solids loading, pretreatment at $200^{\circ} \mathrm{C}$ for $15 \mathrm{~min}$ gave glucose yields approaching $100 \%$ of theoretical (Figure $4(\mathrm{c})$ ). The increase in theoretical glucose yields with increasing solids loading was unexpected and was possibly due to a smaller proportion of cellulose being present within these solid residues (Figure 4(a)). This would have subsequently resulted in a greater ratio of enzyme to cellulose when saccharifying samples pretreated at higher solids loadings, thus increasing the probability of complete enzymatic hydrolysis through more successful enzyme-substrate binding. This hypothesis was supported by the model derived to predict hemicellulose content of the remaining solid residues after pretreatment (Figure 4(b)). This confirmed that hemicellulose content of the remaining residue increased (in an almost linear fashion) with increasing solids loading during the pretreatment step. This suggested a drop in effectiveness of the pretreatment (reduced hemicellulose solubilisation) as solids loading was increased.

The trend in glucose yields with process time at all solids loadings investigated (Figure 4(b)) indicated that extension of reaction times beyond 15 min was unlikely to result in any further increase in glucose yield. A similar model was derived to predict xylose yields across the design space (Figure 4(d)). Once again, sugar yield was maximised at the highest pretreatment solids loading and with treatment times within $13-15 \mathrm{~min}$.

3.2. Acid Catalysed Hydrothermal Pretreatment of BSG. The impact of adding an acid catalyst $(1 \% \mathrm{HCl} \mathrm{v/v)}$ on the hydrothermal pretreatment of BSG was investigated over a range of treatment times $(1-10 \mathrm{~min})$, temperatures (120$200^{\circ} \mathrm{C}$ ), and solids loadings (30-50\% w/v). At such high solids loadings, it was not physically possible to recover the liquid fraction after pretreatment. However, the subsequent biomass was washed extensively with water prior to enzymatic saccharification to remove potential metabolic process inhibitors. 


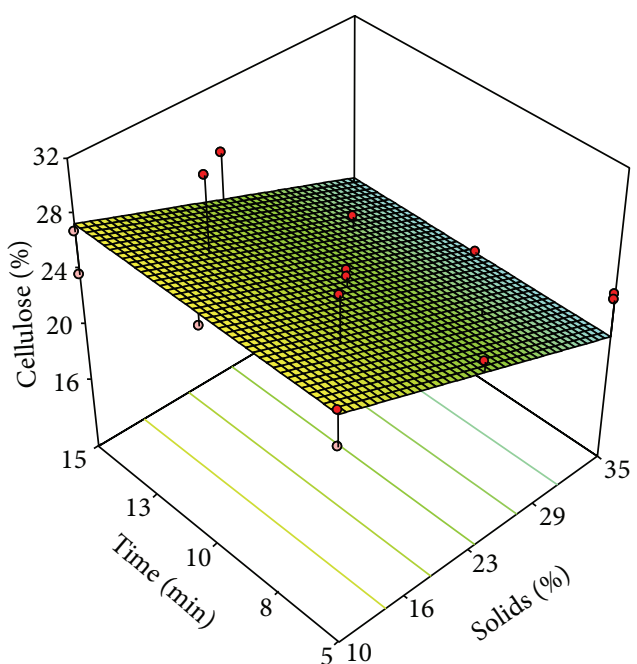

(a) Cellulose

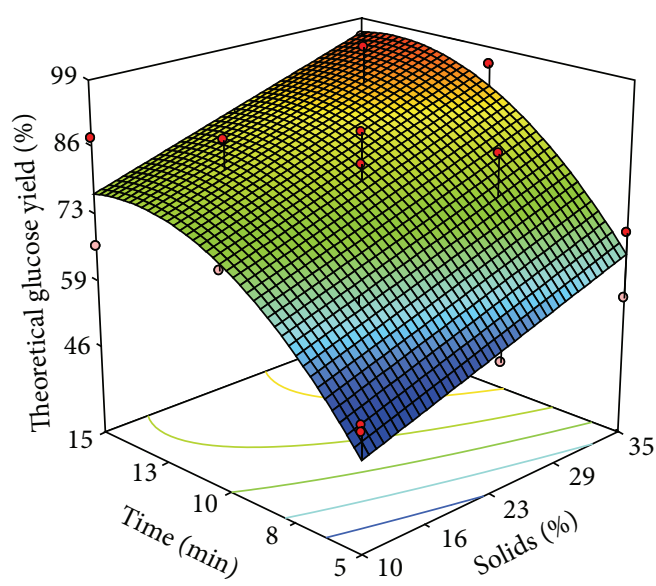

(c) Glucose

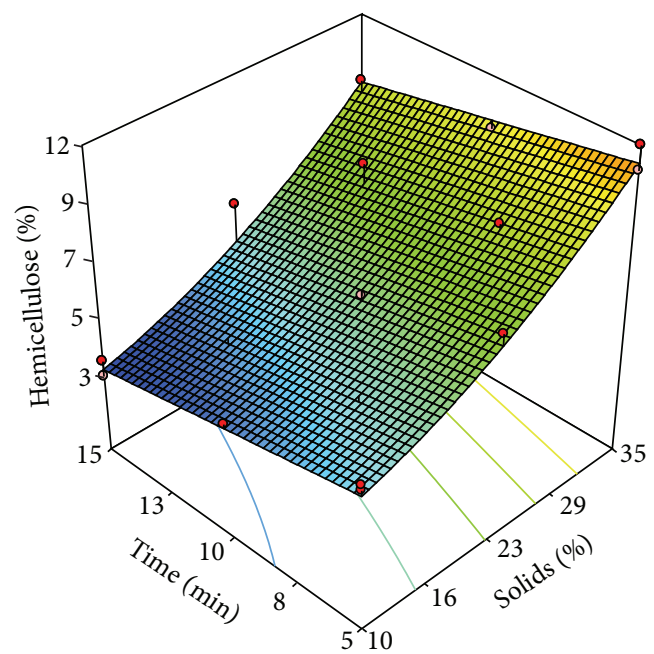

(b) Hemicellulose

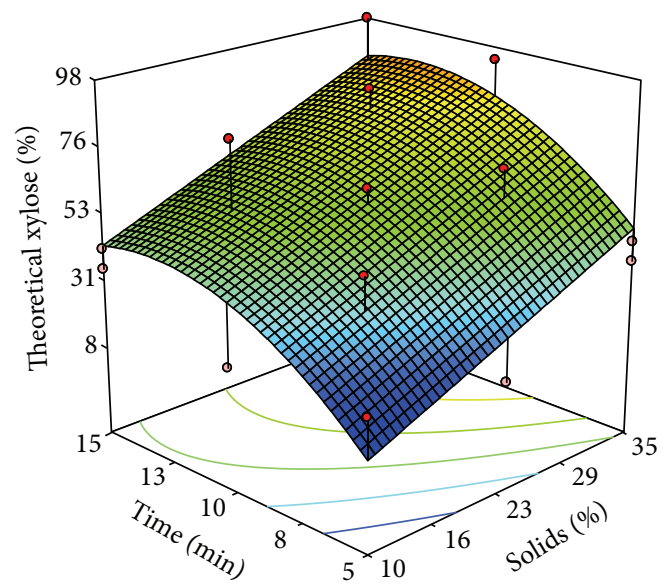

(d) Xylose

Figure 4: Design Expert 3D response surface models showing the effects of the factors (i) \% solids loading (w/v) and (ii) reaction time (min) during $200^{\circ} \mathrm{C}$ pretreatment of BSG (temperature as previously optimised) on (a) \% cellulose content of the solid residue following pretreatment of BSG $\left(R^{2}: 0.56\right)$, (b) \% hemicellulose content of the solid residue following pretreatment of BSG $\left(R^{2}: 0.91\right)$, (c) achieved \% theoretical glucose yield after enzymatic hydrolysis $\left(R^{2}: 0.78\right)$, and (d) achieved \% theoretical xylose yield after enzymatic hydrolysis $\left(R^{2}: 0.75\right)$. Autohydrolytical pretreatment utilized a Monowave 300 microwave synthesis reactor with G30 vessels (Anton Parr). Digestion of pretreated residue: $24 \mathrm{~h}$ incubation $\left(50^{\circ} \mathrm{C}\right)$ using $200 \mathrm{mg}$ residue to $40 \mathrm{~mL}$ of a $1 \mathrm{~g} / \mathrm{L}$ Celluclast solution buffered to $\mathrm{pH} 5.0 \pm 0.1$.

The percentage of theoretical glucose yielded following saccharification is shown as a function of process temperature and time at 30, 40, and 50\% w/v solids loadings (Figure 5). At $30 \% \mathrm{w} / \mathrm{v}$ solids loading, it was apparent that incorporation of the acid catalyst enabled high glucose yields (close to $80 \%$ of theoretical) to be attained at a lower temperature range $\left(140-160^{\circ} \mathrm{C}\right)$ than was required in the absence of $\mathrm{HCl}$ (Figure 5(a)). The acid catalyst acts to enhance the autohydrolysis mechanism through provision of additional protons. However, use of $1 \% \mathrm{HCl}$ at temperatures of 180 $200^{\circ} \mathrm{C}$ decreased theoretical glucose yields as low as ca. $40 \%$ of theoretical, even at relatively short process times (e.g., $1 \mathrm{~min}$ ). The reason for the observed reduction in \% theoretical glucose yields at pretreatment temperatures above $160^{\circ} \mathrm{C}$ at $30 \% \mathrm{w} / \mathrm{v}$ solids loading is unclear, in that a clear fall off in yield was not observed at 40 or $50 \%$ w/v solids loadings. It is possible that the presence of acid at high temperatures causes changes to structural features of the cellulose which impact substrate binding by the cellulase enzymes. There is evidence at high temperatures and all solids loadings (Figure 5) that the achieved theoretical glucose yields decreased with increasing process time. Whatever the actual mechanism might be, it was clearly progressive with increased pretreatment time and was more telling at lower solids contents. At $30 \%$ solids loading, the specific energy absorbed into the biomass would have been the highest which potentially maximised any structural impacts (although the temperature of the treatment was the same in each case, the lower solids loading samples would have contained less biomass for the same overall sample weight). In contrast to the findings at $30 \%$ solids loading, when pretreatment solids loading was increased to $40 \% \mathrm{w} / \mathrm{v}$, a temperature of $180^{\circ} \mathrm{C}$ 


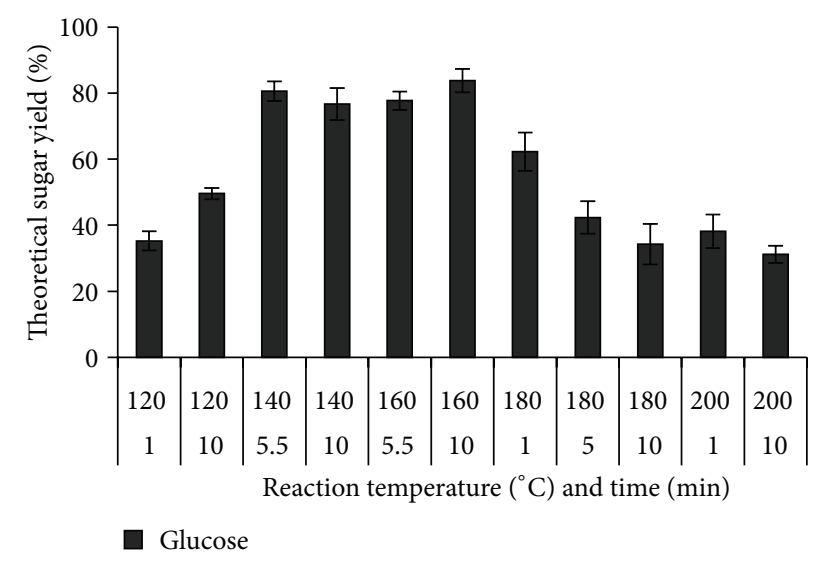

(a) $30 \% \mathrm{w} / \mathrm{v}$ solids loading

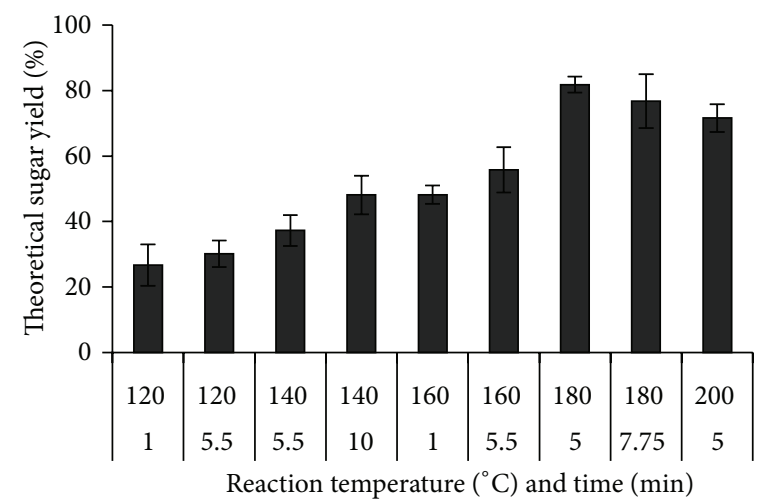

Glucose

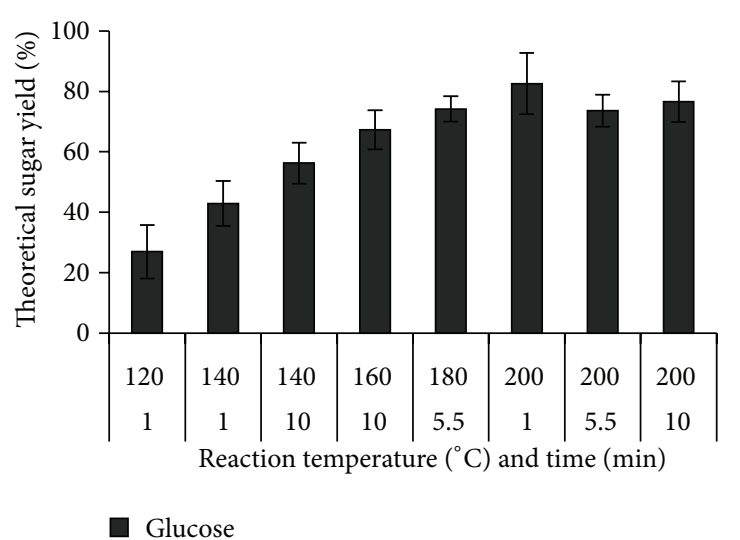

(c) $50 \% \mathrm{w} / \mathrm{v}$ solids loading

FIGURE 5: The impact of reaction temperature $\left(120-200^{\circ} \mathrm{C}\right)$ and reaction time $(1-10 \mathrm{~min})$ at various solids loading during acid catalysed hydrothermal pretreatment of BSG on \% theoretical glucose yields following enzymatic saccharification of the pretreated solid residue. (a) $30 \%$ solids loading, (b) $40 \%$ solids loading, and (c) $50 \%$ solids loading. Data are the mean \pm SD of three replicate measurements. $1 \% \mathrm{HCl}$ hydrothermal pretreatment utilized a Monowave 300 microwave synthesis reactor with G30 vessels (Anton Parr). Enzymatic saccharification of pretreated residue: $24 \mathrm{~h}$ incubation $\left(50^{\circ} \mathrm{C}\right)$ using $200 \mathrm{mg}$ residue to $40 \mathrm{~mL}$ of a $1 \mathrm{~g} / \mathrm{L}$ Celluclast solution buffered to $\mathrm{pH} 5.0 \pm 0.1$.

was required in order to achieve ca. $80 \%$ theoretical glucose yields (Figure $5(\mathrm{~b})$ ). Treatment at $140-160^{\circ} \mathrm{C}$ with $40 \%$ solids loading only achieved approximately $40-60 \%$ of theoretical glucose yields. Furthermore, increasing pretreatment solids loading to $50 \% \mathrm{w} / \mathrm{v}$ required temperatures of $200^{\circ} \mathrm{C}$ to approach $80 \%$ theoretical glucose yields (Figure $5(\mathrm{c})$ ). Thus, at very high solids loadings (40 and $50 \% \mathrm{w} / \mathrm{v}$ ), pretreatment temperature was a more significant parameter than reaction time when using the $1 \% \mathrm{HCl}$ catalyst.

\subsubsection{Total Glucose Concentrations in the Solid Residues} Resulting from 1\% HCl Catalysed Hydrothermal Pretreatment of BSG. In contrast to the results for direct hydrothermal (autohydrolytical) pretreatment, in experiments with addition of $1 \% \mathrm{HCl}$, a positive correlation was observed between cellulose concentrations in the pretreated solid residues and $\%$ theoretical sugar yields achieved following saccharification, at all solids loadings tested (Figures 6(a)-6(c)). Thus, enriching the cellulose fraction of BSG by effectively removing hemicellulose also enhanced enzymatic digestibility of the material and the proportion of cellulose which could then be released as glucose. Whilst the mechanisms of autohydrolysis and acid catalysed hydrothermal pretreatment are considered to be similar in nature $[37,40]$, it appears that the lower $\mathrm{pH}$ attained with $\mathrm{HCl}$ addition enhanced subsequent digestibility of cellulose in this system. Alternatively, other researchers have proposed that the chloride ions added in $\mathrm{HCl}$ exert a catalytic effect, either through nucleophile activity [6] or possibly through an ionic liquid based mechanism, disrupting hydrogen bonding within cellulose microfibrills and further enhancing enzymatic access and thus enzymatic sugar yields $[13,41,42]$.

3.3. Trial Fermentations of Feedstocks. Two optimised pretreatment processes $\left(200^{\circ} \mathrm{C}, 10 \mathrm{~min}\right.$ autohydrolytical and $160^{\circ} \mathrm{C}, 5 \mathrm{~min} 1 \% \mathrm{HCl}$ dilute acid hydrothermal pretreatments, both at $30 \% \mathrm{w} / \mathrm{v}$ solids loading) were chosen for the production of feedstocks to conduct trial fermentations. These treatments were approximately matched in terms of the glucose concentrations attained following saccharification 


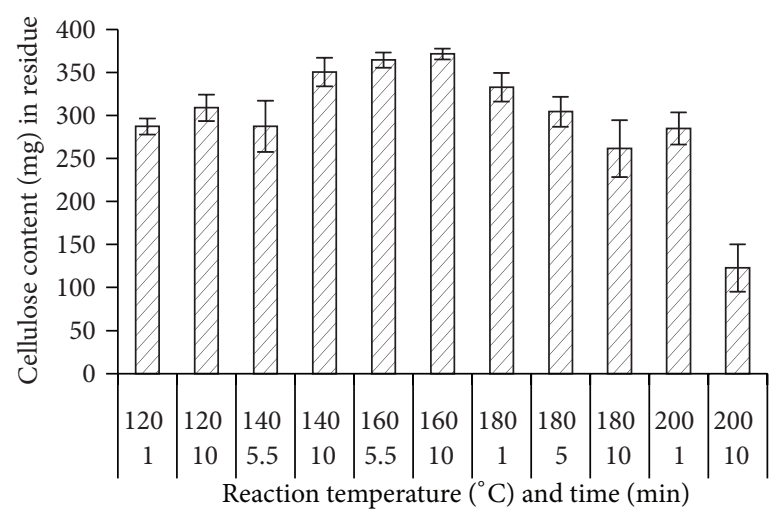

(a) $30 \% \mathrm{w} / \mathrm{v}$ solids loading

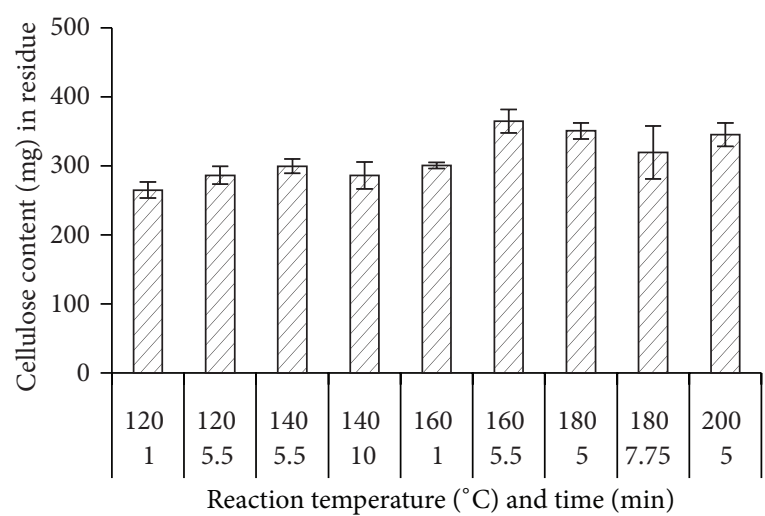

(b) $40 \% \mathrm{w} / \mathrm{v}$ solids loading

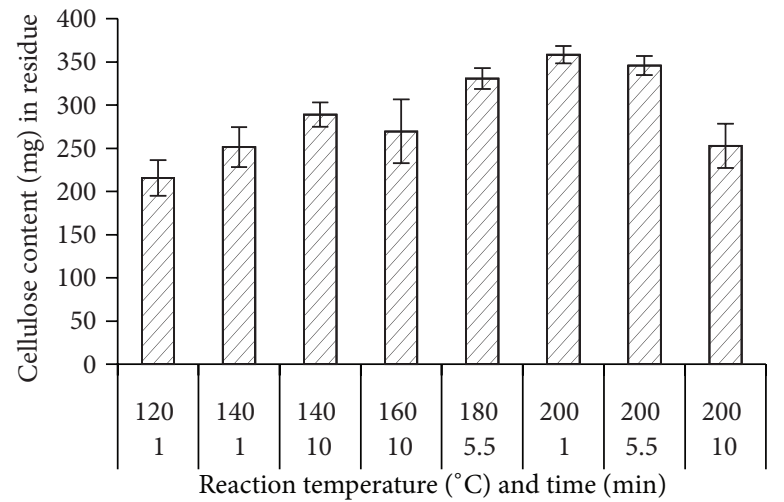

(c) $50 \% \mathrm{w} / \mathrm{v}$ solids loading

FIGURE 6: The impact of reaction temperature $\left(120-200^{\circ} \mathrm{C}\right)$ and reaction time $(1-10 \mathrm{~min})$ at various solids loading during $1 \% \mathrm{HCl}$ acid catalysed hydrothermal pretreatment of BSG on cellulose concentration (expressed as glucose; mg sugar per g solid residue) of the remaining pretreated solid residue after complete acid hydrolysis. (a) 30\% solids loading, (b) 40\% solids loading, and (c) 50\% solids loading. Data are the mean \pm $\mathrm{SD}$ of three replicate measurements. $1 \% \mathrm{HCl}$ hydrothermal pretreatment utilized a Monowave 300 microwave synthesis reactor with G30 vessels (Anton Parr).

$(61 \mathrm{~g} / \mathrm{L}$ and $57 \mathrm{~g} / \mathrm{L}$, resp.; Figure $7(\mathrm{a}))$. In this experiment, realistic constraints were placed upon enzymatic digestion, as opposed to the vast excess of cellulases used previously to compare and contrast the efficacy of pretreatments. Thus, saccharification was conducted at high solids loading (15\% w/v) and with a commercially applicable dose of Novozymes Cellic CTec2.

The trial fermentations were conducted using S. cerevisiae NCYC479. Similar final ethanol concentrations (ca. $22 \mathrm{~g} / \mathrm{L}$ ) resulted from fermentation of either feedstock and this equated to approximately $75 \%$ and $73 \%$ of theoretical ethanol yield (calculated from the initial glucose concentration present in each feedstock) for the Autohydrolysis and $1 \% \mathrm{HCl}$ catalysed pretreatment feedstocks, respectively (Figure $7(\mathrm{a})$ ). A small amount of aerobic respiration and cellular growth at the start of fermentations is thought to explain the proportion of glucose not ultimately fermented to ethanol. This is because, after the biomass was pretreated, the exhaustive washing step would have removed any inhibitors that were generated from the thermal breakdown of sugars. Since the present research did not consider optimisation of either enzymatic hydrolysis or fermentation process conditions, it is a reasonable assumption that these ethanol yields could easily be improved upon. Fermentation progression (followed by vessel weight loss resulting from $\mathrm{CO}_{2}$ evolution) was also similar when comparing the two feedstocks. Each exhibited similar and relatively short lag phases and both attenuated after ca. 10 hours (Figure 7(b)). On average, the autohydrolytical pretreatment generated feedstock resulted in a slightly greater percentage weight loss over the course of fermentation, which likely indicated a greater evolution of $\mathrm{CO}_{2}$; however, this was considered to be due to the very slightly higher glucose concentration present in the initial feedstock. Overall, two highly effective hydrothermal microwave pretreatments were developed for the optimal release of fermentable sugars from BSG.

Overall microwave based autohydrolytical and dilute acid catalysed hydrothermal pretreatment of BSG was indicated to be efficient at producing good subsequent enzymatic saccharification yields at commercially applicable high solids loading rates also with good final ethanol titres and rapid fermentability. Further work involving the determination of the exact dielectric properties of BSG could be conducted which may then allow for specific adjustment of the operational 


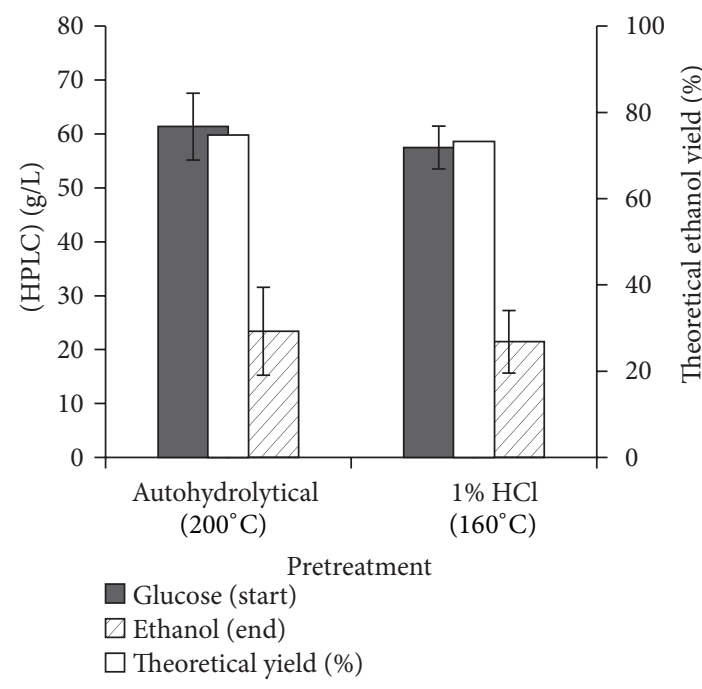

(a)

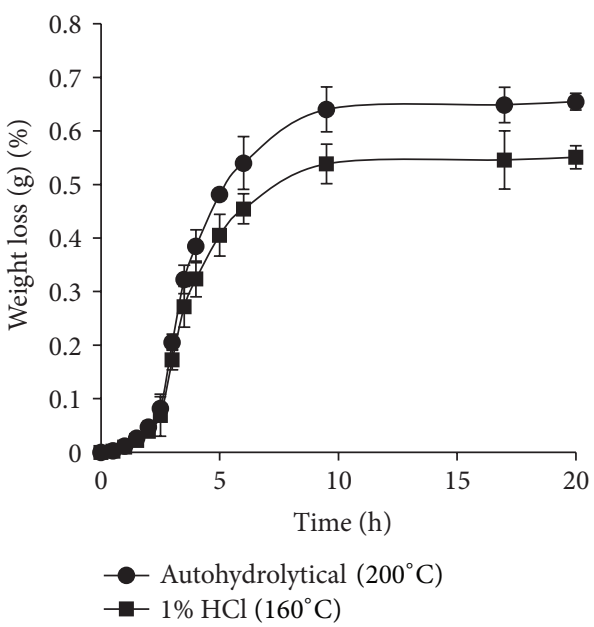

(b)

FIGURE 7: A comparison of yield data (a) and fermentation progression (b) from the trial fermentations (utilizing S. cerevisiae NCYC479) of enzymatic hydrolysates resulting from either optimised autohydrolytical or dilute acid hydrothermal pretreatment processes. (a) Theoretical ethanol yield based on the glucose concentration in the feedstock. (b) Fermentation progression monitored by weight loss of vessels, due to $\mathrm{CO}_{2}$ evolution. Pretreatment: autohydrolytical $\left(200^{\circ} \mathrm{C} 10 \mathrm{~min}\right)$ or $1 \% \mathrm{HCl}$ catalysed hydrothermal $\left(160^{\circ} \mathrm{C} 5 \mathrm{~min}\right)$ at $30 \%$ solids loading (w/v). Enzyme digestion: Novozymes Cellic CTec2 $\left(20 \mu \mathrm{L}\right.$ enzyme per $200 \mathrm{mg}$ residue; $20 \mathrm{FPU} / \mathrm{g}$ biomass, $24 \mathrm{~h}$ incubation at $50^{\circ} \mathrm{C}$, $\left.\mathrm{pH} 5.0 \pm 0.1\right)$. Fermentations conducted at $15^{\circ} \mathrm{C}$ with stirring $(120 \mathrm{rpm})$ and using S. cerevisiae NCYC479 at a pitching rate of $1 \times 10^{6}$ cells $/ \mathrm{mL}$ in $100 \mathrm{~mL}$ of hydrolysate. Data are the mean $\pm \mathrm{SD}$ of three replicate experiments.

parameters of the microwave to further improve the dielectric heating efficiency and thus further reduce the energy input for the pretreatment step whilst still maintaining its efficacy.

\section{Conflict of Interests}

The authors declare that there is no conflict of interests regarding the publication of this paper.

\section{Acknowledgments}

The authors gratefully acknowledge the financial support of SABMiller plc and the University of Nottingham in sponsoring this research. All three authors gratefully acknowledge the support of the BBSRC Sustainable Bioenergy Centre Programme Lignocellulosic Conversion To Ethanol (BB/ G01616X/1).

\section{References}

[1] S. I. Mussatto, G. Dragone, and I. C. Roberto, "Brewers' spent grain: generation, characteristics and potential applications," Journal of Cereal Science, vol. 43, no. 1, pp. 1-14, 2006.

[2] S. Aliyu and M. Bala, "Brewer's spent grain: a review of its potentials and applications," African Journal of Biotechnology, vol. 10, no. 3, pp. 324-331, 2011.

[3] S. I. Mussatto, M. Fernandes, A. M. F. Milagres, and I. C. Roberto, "Effect of hemicellulose and lignin on enzymatic hydrolysis of cellulose from Brewer's spent grain," Enzyme and Microbial Technology, vol. 43, no. 2, pp. 124-129, 2008.
[4] M. Gupta, N. Abu-Ghannam, and E. Gallaghar, "Barley for brewing: characteristic changes during malting, brewing and applications of its by-products," Comprehensive Reviews in Food Science and Food Safety, vol. 9, no. 3, pp. 318-328, 2010.

[5] F. Carvalheiro, M. P. Esteves, J. C. Parajó, H. Pereira, and F. M. Gírio, "Production of oligosaccharides by autohydrolysis of brewery's spent grain," Bioresource Technology, vol. 91, no. 1, pp. 93-100, 2004.

[6] J. S. White, B. K. Yohannan, and G. M. Walker, "Bioconversion of brewer's spent grains to bioethanol," FEMS Yeast Research, vol. 8, no. 7, pp. 1175-1184, 2008.

[7] B. Yang and C. E. Wyman, "Pretreatment: the key to unlocking low-cost cellulosic ethanol," Biofuels, Bioproducts and Biorefining, vol. 2, no. 1, pp. 26-40, 2008.

[8] M. Galbe and G. Zacchi, "Pretreatment: the key to efficient utilization of lignocellulosic materials," Biomass and Bioenergy, vol. 46, pp. 70-78, 2012.

[9] M. Ø. Petersen, J. Larsen, and M. H. Thomsen, “Optimization of hydrothermal pretreatment of wheat straw for production of bioethanol at low water consumption without addition of chemicals," Biomass and Bioenergy, vol. 33, no. 5, pp. 834-840, 2009.

[10] J.-S. Lee, B. Parameswaran, J.-P. Lee, and S.-C. Park, "Recent developments of key technologies on cellulosic ethanol production," Journal of Scientific and Industrial Research, vol. 67, no. 11, pp. 865-873, 2008.

[11] T.-C. Hsu, G.-L. Guo, W.-H. Chen, and W.-S. Hwang, "Effect of dilute acid pretreatment of rice straw on structural properties and enzymatic hydrolysis," Bioresource Technology, vol. 101, no. 13, pp. 4907-4913, 2010.

[12] A. Avci, B. C. Saha, B. S. Dien, G. J. Kennedy, and M. A. Cotta, "Response surface optimization of corn stover pretreatment 
using dilute phosphoric acid for enzymatic hydrolysis and ethanol production," Bioresource Technology, vol. 130, pp. 603612, 2013.

[13] S. Wilkinson, K. A. Smart, and D. J. Cook, "A comparison of dilute acid- and alkali-catalyzed hydrothermal pretreatments for bioethanol production from brewers' spent grains," Journal of the American Society of Brewing Chemists, vol. 72, no. 2, pp. 143-153, 2014.

[14] S. P. S. Chundawat, G. T. Beckham, M. E. Himmel, and B. E. Dale, "Deconstruction of lignocellulosic biomass to fuels and chemicals," Annual Review of Chemical and Biomolecular Engineering, vol. 2, pp. 121-145, 2011.

[15] Ó. J. Sánchez and C. A. Cardona, "Trends in biotechnological production of fuel ethanol from different feedstocks," Bioresource Technology, vol. 99, no. 13, pp. 5270-5295, 2008.

[16] W. Liao, R. Heijungs, and G. Huppes, "Is bioethanol a sustainable energy source? An energy-, exergy-, and emergy-based thermodynamic system analysis," Renewable Energy, vol. 36, no. 12, pp. 3479-3487, 2011.

[17] P. Roy, T. Orikasa, K. Tokuyasu, N. Nakamura, and T. Shiina, "Evaluation of the life cycle of bioethanol produced from rice straws," Bioresource Technology, vol. 110, pp. 239-244, 2012.

[18] J. Tao, S. Yu, and T. Wu, "Review of China's bioethanol development and a case study of fuel supply, demand and distribution of bioethanol expansion by national application of E10," Biomass and Bioenergy, vol. 35, no. 9, pp. 3810-3829, 2011.

[19] F. Coppola, S. Bastianoni, and H. Østergård, "Sustainability of bioethanol production from wheat with recycled residues as evaluated by Emergy assessment," Biomass and Bioenergy, vol. 33, no. 11, pp. 1626-1642, 2009.

[20] H. Chen and W. Qiu, "Key technologies for bioethanol production from lignocellulose," Biotechnology Advances, vol. 28, no. 5, pp. 556-562, 2010.

[21] H. A.-H. Ibrahim, "Pretreatment of straw for bioethanol production," Energy Procedia, vol. 14, pp. 542-551, 2012.

[22] M. Balat, "Production of bioethanol from lignocellulosic materials via the biochemical pathway: a review," Energy Conversion and Management, vol. 52, no. 2, pp. 858-875, 2011.

[23] F. Talebnia, D. Karakashev, and I. Angelidaki, "Production of bioethanol from wheat straw: an overview on pretreatment, hydrolysis and fermentation," Bioresource Technology, vol. 101, no. 13, pp. 4744-4753, 2010.

[24] I. Janker-Obermeier, V. Sieber, M. Faulstich, and D. Schieder, "Solubilization of hemicellulose and lignin from wheat straw through microwave-assisted alkali treatment," Industrial Crops and Products, vol. 39, no. 1, pp. 198-203, 2012.

[25] M. Nüchter, U. Müller, B. Ondruschka, A. Tied, and W. Lautenschläger, "Microwave-assisted chemical reactions," Chemical Engineering and Technology, vol. 26, no. 12, pp. 1207-1216, 2003.

[26] X. Lu, B. Xi, Y. Zhang, and I. Angelidaki, "Microwave pretreatment of rape straw for bioethanol production: focus on energy efficiency," Bioresource Technology, vol. 102, no. 17, pp. 79377940, 2011.

[27] P. Binod, K. Satyanagalakshmi, R. Sindhu, K. U. Janu, R. K. Sukumaran, and A. Pandey, "Short duration microwave assisted pretreatment enhances the enzymatic saccharification and fermentable sugar yield from sugarcane bagasse," Renewable Energy, vol. 37, no. 1, pp. 109-116, 2012.

[28] D. Jackowiak, D. Bassard, A. Pauss, and T. Ribeiro, "Optimisation of a microwave pretreatment of wheat straw for methane production," Bioresource Technology, vol. 102, no. 12, pp. 67506756, 2011.
[29] J. Xu, H. Chen, Z. Kádár, A. B. Thomsen, J. E. Schmidt, and H. Peng, "Optimization of microwave pretreatment on wheat straw for ethanol production," Biomass and Bioenergy, vol. 35, no. 9, pp. 3859-3864, 2011.

[30] E. Coelho, M. A. M. Rocha, J. A. Saraiva, and M. A. Coimbra, "Microwave superheated water and dilute alkali extraction of brewers' spent grain arabinoxylans and arabinoxylooligosaccharides," Carbohydrate Polymers, vol. 99, pp. 415-422, 2014.

[31] T. K. Ghose, "Measurement of cellulase activities," Pure and Applied Chemistry, vol. 59, no. 2, pp. 257-268, 1987.

[32] M. Dubois, K. A. Gilles, J. K. Hamilton, P. A. Rebers, and F. Smith, "Colorimetric method for determination of sugars and related substances," Analytical Chemistry, vol. 28, no. 3, pp. 350356, 1956.

[33] F. Carvalheiro, L. C. Duarte, and F. M. Gírio, "Hemicellulose biorefineries: a review on biomass pretreatments," Journal of Scientific and Industrial Research, vol. 67, no. 11, pp. 849-864, 2008.

[34] S. A. Allen, W. Clark, J. M. McCaffery et al., "Furfural induces reactive oxygen species accumulation and cellular damage in Saccharomyces cerevisiae," Biotechnology for Biofuels, vol. 3, article 2, 2010.

[35] Z. L. Liu, "Genomic adaptation of ethanologenic yeast to biomass conversion inhibitors," Applied Microbiology and Biotechnology, vol. 73, no. 1, pp. 27-36, 2006.

[36] E. Palmqvist and B. Hahn-Hägerdal, "Fermentation of lignocellulosic hydrolysates. II: inhibitors and mechanisms of inhibition," Bioresource Technology, vol. 74, no. 1, pp. 25-33, 2000.

[37] G. Garrote, H. Domínguez, and J. C. Parajó, "Hydrothermal processing of lignocellulosic materials," European Journal of Wood and Wood Products, vol. 57, no. 3, pp. 191-202, 1999.

[38] O. Yemiş and G. Mazza, "Optimization of furfural and 5hydroxymethylfurfural production from wheat straw by a microwave-assisted process," Bioresource Technology, vol. 109, pp. 215-223, 2012.

[39] J. N. Chheda, Y. Román-Leshkov, and J. A. Dumesic, "Production of 5-hydroxymethylfurfural and furfural by dehydration of biomass-derived mono-and poly-saccharides," Green Chemistry, vol. 9, no. 4, pp. 342-350, 2007.

[40] A. T. W. M. Hendriks and G. Zeeman, "Pretreatments to enhance the digestibility of lignocellulosic biomass," Bioresource Technology, vol. 100, no. 1, pp. 10-18, 2009.

[41] Y. Su, H. M. Brown, G. Li et al., "Accelerated cellulose depolymerization catalyzed by paired metal chlorides in ionic liquid solvent," Applied Catalysis A: General, vol. 391, no. 1-2, pp. 436442, 2011.

[42] D.-T. Liu, K.-F. Xia, W.-H. Cai, R.-D. Yang, L.-Q. Wang, and B. Wang, "Investigations about dissolution of cellulose in the 1allyl-3- alkylimidazolium chloride ionic liquids," Carbohydrate Polymers, vol. 87, no. 2, pp. 1058-1064, 2012. 


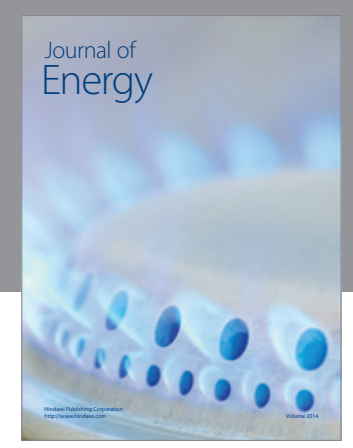

Journal of

Industrial Engineering
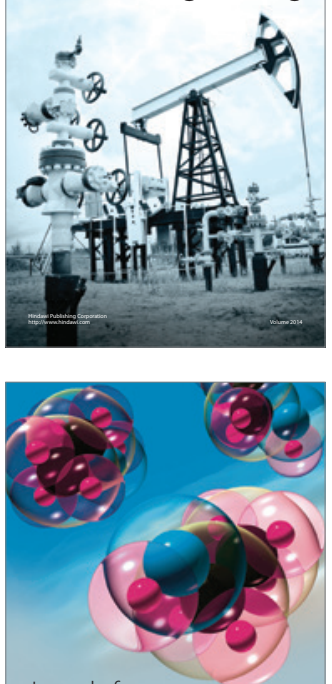

Fuels
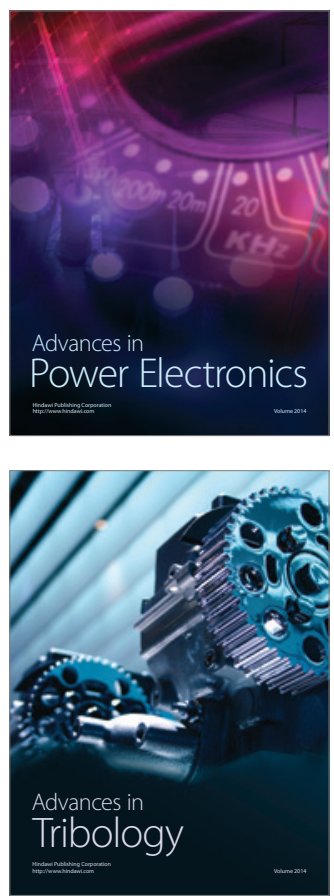

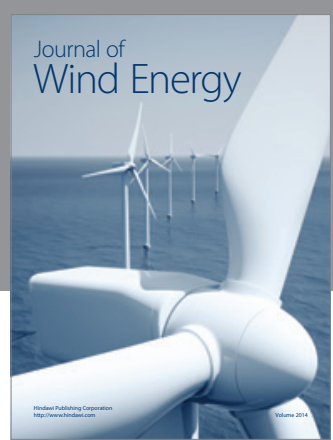

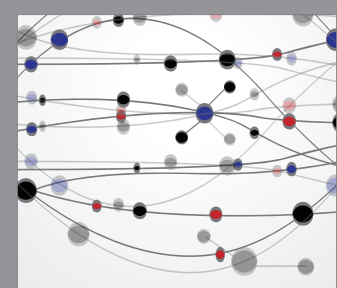

The Scientific World Journal

Submit your manuscripts at http://www.hindawi.com

Journal of

Structures
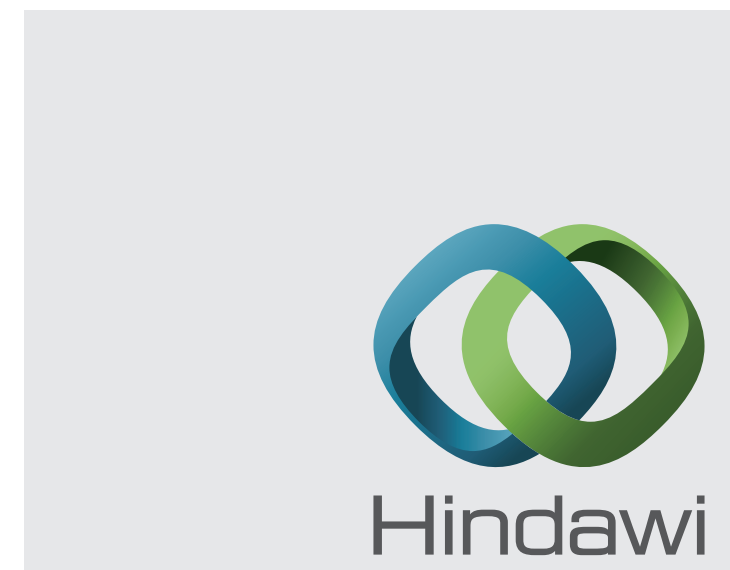

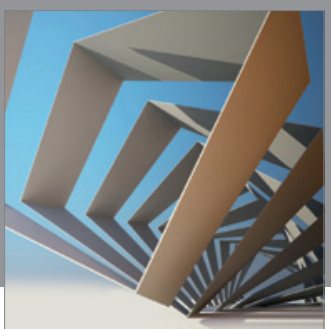

Rotating

Machinery
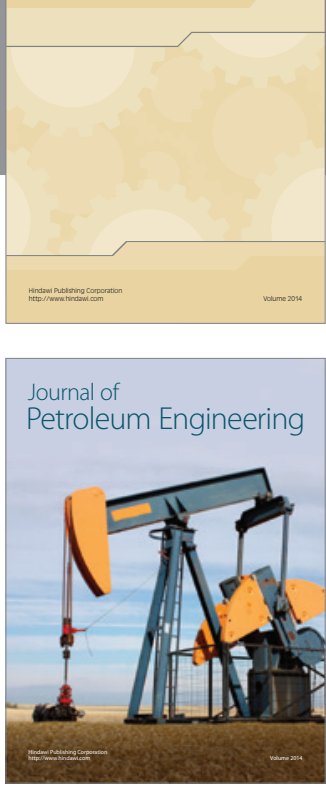

Journal of

Solar Energy
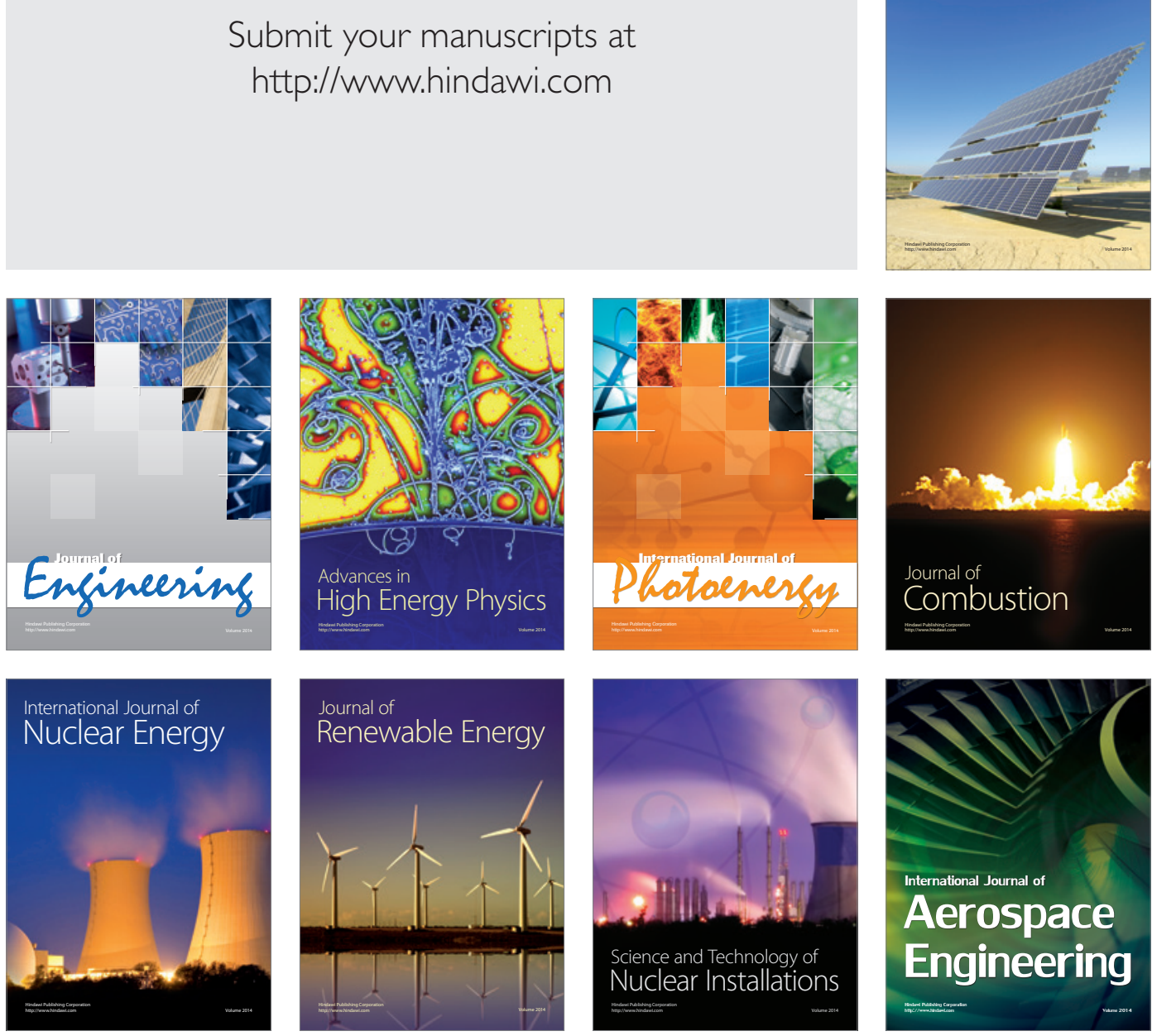